\title{
Mediated communication and mediated communities in the information age
}

\section{Gábor Szécsi}

\author{
Institute for Philosophical Research of the \\ Hungarian Academy of Sciences; University of \\ Pécs, Faculty of Adult Education and Human \\ Resources, Hungary. \\ szecsi.gabor@,feek.pte.hu
}

\begin{abstract}
This article argues that electronically mediated communication contributes to the construction of new, mediated forms of communities which are based on the synthesis of virtual and physical communities. The appearance of these new forms of communities leads to a new conceptualization of the relation between self and community. The aim of this article is to show the basis and effects of this process by examining the proposition that the expansion of electronic communication and the linguistic convergences induced by new communication technologies contribute to the construction of new forms of communities based on the interaction, or operational synthesis, of virtual and physical communities.
\end{abstract}

\section{Introduction}

The communications revolution of the $20^{\text {th }}$ century has had significant impact on the conceptualization of globalization. In other words, the recent conceptualization of globalization is rooted in a process of change which has brought an expansion of electronic communication-based culture, abolishing the dominance of printed literacy. It seems that by using electronic technologies (radio, television, the internet, mobile telephony) and the specific pictorial language of multimedia communication, we can increasingly eliminate the spatial and temporal bonds of the global exchange of information. By deploying new technological dimensions of communication, an opportunity presents itself to simultaneously follow various global processes and events. This new, simultaneous information world is referred to as 'global village' by Marshall McLuhan in his works (McLuhan 1962; 1964;

Szécsi, G. (2016). Mediated communication and mediated communities in the information age. The Journal of Community Informatics, 12(1), 157-167.

Date submitted: 2013-01-25. Date accepted: 2016-04-04.

Copyright (C), 2016 (the author as stated). Licensed under the Creative Commons AttributionNonCommercial-ShareAlike 2.5. Available at: http://www.ci-journal.net/index.php/ciej/article/view/1021 
McLuhan and Fiore 1967) As he points out, electronic technologies "abolish the spatial dimension, rather enlarge it" (McLuhan 1964: 255), and his perception that the world has 'imploded' gives rise to the famous statement that: " 'Time' has ceased, 'space' has vanished. We now live in a global village... a simultaneous happening" (McLuhan and Fiore 1967:63).Recognition of the importance of McLuhan's conception leads many theorists, who are concerned to study communication via the internet, to insist on the continued relevance of McLuhan's work for understanding media in the digital age (Levinson 1999; Kerckhove 1995).

It has become both for McLuhan and his followers that the new global-communityconsciousness, growing out of the use of electronic media supported by the effects of the information economy, will accelerate the technologically and economically based process of globalization. Gradually, we will become citizens of the McLuhanesque global village, and as such we can witness the birth of a new universal civilization. Global communication is the most important manifestation of this new civilization based on western patterns. In this new communication galaxy, the flow of information becomes quicker and continuous; the universally understandable iconic world, icon-based information and multimedia-based know-how transfer play ever-going roles. The rules of this special iconic language which supersedes cultural boundaries will transform our different societies and cultures into a 'global village'.

Accordingly, the notion of a new kind of worldwide flow of information determines the meaning of the term 'globalization'. There are a large number of semantic layers, however, which have settled on this conceptual base. Although nowadays we use the word 'globalization' to refer to phenomena to which the social sciences have created their own categories (e.g. the division of labour, integration, international cooperation), the notion of globalization is inseparably attached to our expectations regarding the effects of electronic media on the creation of the conditions for worldwide communication.

Though the real-time occurrence and proximity created by electronic media have not been followed by the reconciliation of certain cultures, and especially not by the economic balancing of different regions of the world, the meaning of the word 'globalization' still suggest our faith in the positive developments of global communication and in a knowledgebased social world model. This meaning is rooted in our belief that the worldwide flow of information creates a specific atmosphere of acceptance in which the characteristic approaches that are dividing nations and cultures do not prevail, but rather those common problems move into focus which are of concern to all of us. In the spirit of this, users of the new technologies feel themselves to be members of a global community, the borders of which supersede the common human relationships defined and articulated by new, mediated forms of communities.

In this article, I try to support the above assumption by discerning the effects that are occur to our conceptualization of community by the use of electronic media. To clarify the nature of this new conceptualization, I propose as a starting point that the expansion of electronic communication has transformed our notion of the relation between place and community. With a greater proportion of our communicative acts taking place via electronic media, physical co-presence, the co-located interpersonal relations are diminishing as determinants of the nature of human interactions. 
It would seem that in the space of electronic media, community should be understood as a mediated network of interactions between individuals who uniformly accept and apply some rules for the communicative actions aiming at the effective exchange of information. In other words, there is an inner relation between the criteria of community and the global and local conditions for an effective method of information exchange. And these global and local conditions transform our notions surrounding a community's structure and life.

The electronically mediated communication, as an inherent part of real life in today's world, contributes to the construction of new, mediated forms of communities which are based on the interaction or operational synthesis of virtual and physical communities. The appearance of these new forms of communities leads to the new conceptualization of the relation between self and community. In the age of electronically mediated communication, the essence of community is a kind of networked individualism in which the networked individuals can chose their own communities, rather than are fitted into them with others involuntarily. Therefore the new, mediated form of community implies an individual-centered existence and weaker social ties, as new technologies foster communication links outside the individuals' immediate social surrounds.

Accordingly, electronic communication creates a new context in which our notions of culture, community, society, human interactions become more complex. These more complex notions can be regarded as the bases of the idea of the global and local information communities in which the communication attitudes of a person are determined by their impression of their self as permanently available individual whose communicative acts are embedded in a special information net. The aim of this paper is to show the basis and effects of this process by examining the proposition that the expansion of electronic communication and the linguistic convergences induced by new communication technologies contribute to the construction of new forms of communities based on the interaction, or operational synthesis, of virtual and physical communities.

\section{Towards an operational synthesis of virtual and physical communities}

By the using electronic communication technologies, an individual's conceptualization of community is embedded strongly in the associative system of conceptual relations that represent the various situations of information exchange. With such a conceptualization of mediated community is conceived as a network of communicative interactions. I want to argue here that the ways of understanding of the interactions between virtual and physical communities move beyond the traditional sociological conceptualization of community-asinterpersonal towards a conceptualization of mediated communities that are based on the interaction or the operational synthesis of virtual and physical communities.

In the information age, the electronically mediated communication contributes to the construction of new, hybrid virtual and physical forms of communities which have some level of social capital, and the functions of which are to foster communities of interest, to spread information, and to promote equality of status, all of which work to enhance social capital, that is, the ability of individuals to associate and work together for common communal purposes despite the lack of direct physical orientation. The appearance of these new forms of communities leads to the new conceptualization of the relationship between individual and community. In the age of electronically mediated communication, the essence 
of community is a kind of networked individualism in which individuals can choose their own communities, rather than being involuntarily fitted into them with others. Therefore the new mediated form of community implies an individual-centered existence and weaker social ties. New technologies foster communication links outside individuals' immediate social surroundings.

Just as traditional theories of community regard community and society as distinct forms (Tönnies 2001), it is also easy to consider physical and virtual communities as mutually exclusive forms of social organization. In this view, physical community can exist only by virtue of physical co-location in space, and is based on people's natural association through sameness and residential solidarity. Virtual communities created by electronically mediated communication, however, attempt to break some of the boundaries of geographic location, gender, and ethnicity established in physical communities. In other words, physical communities are based on shared social and physical boundaries, whereas virtual communities are based on shared social practices and interest.

Considering the influence of mediated communication on our community-concept, however, many theorists believe that we need a synthesis of physical and virtual communities in order to truly inhabit our experiences. Manuel Castells, for example, holds that we need a 'bridge' between physical and virtual places in order to unify our experience, because virtual communities only deal in fragmented individuals when they are opposed to real life (Castells 2000). Others, like Amitai Etzioni (2001), James E. Katz. (Katz et al. 2004), Barry Wellman, and Milena Gulia (1999), Caroline Haythornthwaite and Lori Kendall (2010) emphasize that the best communities are indeed the hybrids of physical and virtual communities. They see the ideal communities as virtual communities enhancing physical communities. According to Katz et al., since the electronically mediated communication becomes inherently part of real life in today's world, "we need an operational synthesis of virtual and physical communities in order to have fulfilling, embodied experiences all of the time" (Katz et al. 2004: 362). In this view, in the age of electronically mediated communication, the dividing line between virtual and physical communities becomes increasingly indistinct. Therefore, as Mark Poster shows it, the mediated individuals imagine their virtual communities as real (Poster 2001). That is, the role of communication as meaningful and value-based in virtual communities also works to construct physical communities as well.

It is obvious that through this new synthesis of virtual and physical communities, electronically mediated communication contributes to a new construction of the self. The mediatization of communities leads to fractured and fragmented selves, because it opens up many other possible communities in which to participate. The new communication technologies enable individuals to participate in alterior alternative? systems of values, belief, and desires. As Kenneth J. Gergen notes: "New affective bonds are created outside one's social surrounds. The result is that the centered sense of a bounded self slowly gives way to a 'multiphrenia' of partial and conflicted senses of self. Identity becomes fluid, shifting in a chameleon-like way from one social context to another" (Gergen 2003: 111).

Thanks to these changes, the networked individual is attached less and less to the place and position appointed by his own social ties. Through his multi-channel communicative acts he can become acquainted with more and more communal forms, ways of life, traditions and values in the light of which he can choose more deliberately from among the competing local 
communities. And this more deliberate choice becomes a part of the more and more complex and multi-layered identity of the networked individual. As Joshua Meyrowitz writes on the multiple, multi-layered, fluid, and endlessly adjustable senses of the media-networked individuals' identity: "Rather than needing to choose between local, place-defined identities and more distant ones, we can have them all, not just in rapid sequence but in overlapping experiences. We can attend a local zoning board meeting, embodying the role of local concerned citizen, as we cruise the internet on a wireless-enabled laptop enacting other, non-local identities. And we can merge the two as we draw on distant information to inform the local board of how other communities handle similar issues and regulations. All the while, we can remain accessible to friends, family, and colleagues from anywhere via a textmessage enabled mobile phone." (Meyrowitz 2005: 28)

New localities are in the making which are particular in many ways, and also are influenced by global processes and global consciousness. Thus the new local communities organized in the space of electronic communication, on the one hand, strengthen the local attachments, the local identity and, on the other hand, can be regarded as integrated elements of the virtual communities created by global information exchange. Consequently, the global virtual community serves as a kind of comparison background for the local communities organized in the age of electronic media. With globalized communication space, electronic media give the networked individual external perspectives from which to judge and define his own local community. In other words, the twentieth-century expansion of electronic communication technologies, as Meyrowitz writes, 'have placed an interconnected global matrix over local experience' (Meyrowitz 2005: 23).

The networked individual determines the characteristics of his own local community in the light of information acquired in the global communication space. The global perspective created by electronic communication has transformed not only the community-definitions but the individual's relation to social rules. In the space of electronic communication, there is a new possibility to change the rules of social perception and the national institutions of political and cultural domination as a consequence of new global perspectives. This last sentence is a bit repetitive

One of the most characteristic features of the virtual space of electronic communication is that it lacks the compulsory categorization system and the classificatory forms and norms of a print society. In the media-networked global and local communities, it is difficult to maintain several traditional categorial distinctions that characterized the print societies. That is, as electronic communication technologies expand, the dividing line between several political and social categories becomes increasingly indistinct.

The age of electronic communication is the age of opening up categorical and classification boundaries. In this new space of communication, the traditional distinctions between private and public, between children and adult experiences, and between male and female spheres collapse and disappear. In the age of electronic media, as Meyrowitz suggests, we are experiencing "both macro-level homogenization of identities and micro-level fragmentation of them" (Meyrowitz 2005: 29).

A new virtual social space is in the making, strengthening cohesion of competing local communities, and in which, therefore, the influence of traditional social and political 
institutes declines. The new communication situations created by the use of electronic technologies foster greater emotional attachments, to the local community which we choose from among the competing communities deliberately without social and political restriction.

Thus in this new social space there is a fundamentally new possibilities to change the rules of social perception and the conceptualization of the relation between the local communities and traditional political institutes of state. Thanks to these changes, the networked individual is attached to the place and position appointed by his own social class less and less. Through his multi-channel communicative acts he can become acquainted with more and more communal forms, ways of life, traditions and values, in the light of which he can choose more deliberately from among the competing local communities. And this more deliberate choice becomes a part of the more and more complex and multi-layered identity of the networked individual.

By using electronic communication technologies, a networked individual becomes a part of a network of interactions between humans who uniformly accept and apply some rules for the communicative acts aiming at the effective exchange of information. In other words, the media-networked individuals become members of a virtual community that is determined both by the global and the local conditions for an effective method of information exchange.

Regarding the conceptualization of this new virtual community, Nicola Green, for example, argues for a new view of community, in which the significance of locality and interpersonality recedes to the benefit of symbolic processes (Green 2003). As Green points out: "As is the case with internet and 'virtual' communities then, understandings of mobile 'communities' should move beyond the conceptualisation of 'communities-as-interest-groups' (secured via the authentication of the embodied liberal individual and their 'right to privacy'), and indeed beyond a traditional sociological conceptualisation of 'communitiesas-interpersonal-and-co-located' (secured via relations based on face-to-face interaction in kinship or social commonality). Rather, we should move towards a conceptualisation of 'communities-as-trust-processes' (secured via the mutual, reciprocal and multiple negotiation of mediated, interpersonal, and organization uncertainty and risk)." (Green 2003: 55)

This new conceptualization moves beyond the traditional definition of community, according to which, as Green writes, community as "an ideal type of relation corresponding to "natural will', is distinguished by an appeal to a totality of cultural history in the collective memory of tradition, is defined through common property, family, custom and fellowship, and is bound by consensus, language and ritual" (Green 2003: 53). The basis of this conceptualization is a complex system of associative conceptual relations that includes our concept of community, and integrates the conceptual representations of human interactions which determine the life of community both in a direct and indirect way.

The medium of the new conceptualization is a specific pictorial language, the semantic structure of which offers new opportunities to grasp and understand the complex concept of community. 


\section{Linguistic convergences in mediated communities}

One of the most important criteria of the new, more deliberate attachment to the local is the deliberate application of the ways of usage that create new local communities in the age of electronic communication. The appearance of these new ways of usage can be regarded as a consequence of networked individuals' deliberate choice to want to join in the global information exchange, and to express conceptual relations and emotions as a member of a local community by using new linguistic forms. These new ways of usage are rooted in the communication language of electronic media that can be regarded as a result of the convergence of two special forms of electronic communication, secondary orality induced by radio, television and 'Netspeak' induced by the Internet and mobile telephony.Thus we consider the new linguistic culture of electronic communication as one of the most important conditions of the conceptual and social convergences experienced in the space of electronic media. It seemed that this new linguistic culture is both the basic both of the global perspective created by electronic communication and the cohesion of the new, mediated communities that are strengthened by deliberate choices of the networked individuals.

In this new linguistic culture, the original social function of language, namely, the building and maintaining of the cohesion of human community, becomes important development. This is because in print societies, language has moved away from its original function as a consequence of the appearance of the oral-literal bilingualism and the linguistic asymmetry rooted in the social dominance of the standard dialect of literacy. That is, instead of strengthening community's cohesion, bilingualism disintegrates primary human communities as the use of their own dialects is overtly stigmatized in light of the socially preferred standard dialect of literacy. This communication culture that forces the whole society and all communities to use one preferred language variety goes against the individual's biologically encoded need to belong to a primary community.

The original social function of language, however, has survived the linguistic asymmetry as developed in print societies. People hold to their everyday use of language, even if they judge their own dialectical varieties incorrect under the pressure of the overt prestige of the standard. Since the members of small local communities generally communicate with one another orally, the linguistic conventions characterizing these communities have survived in the age of standard linguistic varieties too. In these small local communities the importance of cohesion-strengthening, local values outstrips the external social values that are symbolized by the standard forms of written communication. This phenomenon is experienced especially in small, isolated rural and suburban communities where the prestige of the non-standard variety of usage can be regarded, at the same time, as a symbol of communal identity (Trudgill 1980; Milroy and Milroy 1991) .

In the space of electronic communication, literacy that generated the asymmetry of linguistic norms of oral and written communication seems to be losing its power, as the prestige of the identity-strengthening ways of usage that characterizes small communities and group grows. The expansion of the non-standard varieties of language preferred by the networked individuals is accelerated by the use of electronic media (internet, mobile telephone). This process leading to decline of the prestige of literacy is accelerated by the convergence of the oral and the written communication technologies that affects usage since the new kind of orality created by the use of radio and television or, especially, use of multimedia messaging, 
the synchronous-complementary transmission of speech, text and pictures in the space of mobile and internet communication.

There are well-perceptible, concrete signs of this convergence of the features of the oral and the written usage. Let us consider the texts that are mediated by the internet or mobile telephone. The texts of many e-mail and SMS message actually belong to the domain of speech and not to the domain of written texts. The grammatical and stylistic characteristics of these messages can be regarded as the marks of a special kind of oral communication. These grammatical and stylistic elements, however, are integrated into the texts mediated by new communication technologies in a more deliberate waythan into any oral utterances. By using these elements, the utterer intends to show that he wishes to accept and apply the norms and the rules of a linguistic community organized by e-mail and SMS communication. That is to say, he uses these grammatical and stylistic elements of linguistic communication to make it unambiguous that he is attached to a community accepting some forms of usage and that this attachment is a consequence of a deliberate choice.

The linguistic forms accepted in this way strongly affect everyday usage. The use of the aforementioned linguistic forms leaves its mark on written communication, ç leadings to convergence between orality and literacy. What can be regarded as an outcome of this process is the increasingly indistinct dividing line between the linguistic characteristics of oral and written communication. A new communication culture is in the making which integrates the forms of language used in oral utterances and in written texts. One of the most characteristic features of this communication culture is that the advent of multimedia communication has resulted in a strong interaction between picture and language in the process of oral and written messaging. Thanks to the appearance of this specific, pictorial language, the process of the convergence and synthesis of the linguistic features of oral and written forms of communication is accelerated.

An important oral medium of this new communication culture is referred as 'secondary orality' by Walter J. Ong in his classic work, Orality and Literacy (Ong 1982). The new kind of orality, accordingly, is not succeeded by, but completes, the cultures of literacy. As Ong writes: "[...] with telephone, radio, television and various kinds of sound tape, electronic technology has brought us into the age of 'secondary orality'. This new orality has striking resemblances to the old in its participatory mystique, its fostering of a communal sense, its concentration on the present moment and even is use of formulas. But it is essentially a more deliberate and self-conscious orality, based permanently on the use of writing and print, which are essential for the manufacture and operation of the equipment and for its use as well." (Ong 1982: 135-136)

The other significant medium of the new communication culture, which is called 'Netspeak' by David Crystal (2004) in his Language and the Internet, however, is better seen as a novel language combining written, spoken, and electronic properties. As Crystal notes, the term "Netspeak", which is an alternative to "Internet language", "cyberspeak", "electronic language", "computer-mediated communication", and "other cumbersome locutions" (p. 17), refers to a new species of communication that is "better seen as written language which has been pulled some way in the direction of speech than as spoken language, which has been written down" (p. 47). Electronic texts, however, are not the same as other kinds of texts, because, as Marilyn Deegan (2000) points out, they display simultaneity, fluidity, and non- 
degradability in copying, and they have permeable boundaries. These properties, as Crystal (2004) writes, "have consequences for language, and these combine with those associated with speech and writing to make Netspeak a genuine 'third medium"' (p. 48) that is more than aggregate of spoken and written features.

In my view, the new linguistic culture of electronic communication can be regarded as a fruit of the convergence of spoken language of secondary orality and written language of 'Netspeak'. It seems that there are well-perceptible, concrete signs of this convergence of the features of oral and written usage. Let us consider texts that are mediated by the Internet or mobile telephony. The text used in many e-mail and SMS messages actually belongs to the domain of speech and not to the domain of written language. The grammatical and stylistic characteristics of these messages can be regarded as the marks of a special kind of a new communication culture (e.g., the various types of abbreviations, distinctive graphology, the new lexicon and means of word-creation that belongs exclusively to the use of new communication technologies simple, addictive grammar etc.). These grammatical and stylistic elements, however, are integrated into texts that are mediated by new communication technologies more deliberately than into oral utterances. By using these elements, the utterer intends to show that he wishes to accept and apply the norms and rules of a linguistic community organised by e-mail and SMS communication. That is to say, he uses these grammatical and stylistic elements to make it unambiguous that he is attached to a community accepting some forms of usage, and that this attachment is a consequence of a deliberate choice.

This kind of usage leads, on the one hand, to the appearance of new terms in language and, on the other hand, to the novel use of available lexical elements of language. In the latter process, the meanings of some words multiply with more and more conceptual relations. This is why the usage of the word 'community' entails the intention of understanding of the overall or global criteria of community in the age of electronic media. These criteria can be attributed to the specific features of communicational space which is globalized by the use of television, the Internet, and mobile telephones. In other words, there is an inner relation between these criteria and the global conditions for an effective method of information exchange. These global conditions (a common information basis, collective trust relations, etc.) transform our notions surrounding the structure and life of community.

Focusing on the inner relation between the new conceptualization of the criteria of community and our notions regarding the global conditions for an effective method of information exchange, we can suggest, for example, the following definition: community is a network of interactions among individuals who uniformly accept and apply some rules for the communicative acts aiming at the effective exchange of information.

Of course, the complex experience of community everyone has urges us to propose many other definitions. And it is obvious that these definitions approach the community-organizing role of information in different way. They have, however, one thing in common: they all must be founded on the analysis of the conceptual and linguistic changes that transform the structure of our minds in the mediated communities of the electronic era. Because these linguistic changes can be regarded as bases of the mediatization of communities and the adopting of the idea of a global, community building language in the new media space. But what kind of language would best serve as a global language in the network of mediated 
communities? Amitai Etzioni, for example, argues for adopting English as a shared, secondary global language in the information age (Etzioni 2008). As Etzioni points out: " $a$ key element of building a global community atop local communities requires that the various nations involved choose the same second language" (Etzioni 2008: 124). This second language, of course, does not replace the particularistic, identity constituting primary languages of local and national communities, rather it is best considered as an additional language. Nevertheless an opposition can be experienced to adopting such an additional language in many nations. According to Etzioni, 'this opposition often conflates preventing English penetration into the primary language with resisting it as second language' (Etzioni 2008: 124). Whereas this opposition, as Etzioni writes, "delays overcoming the 'babel' effects at great cost to the transparency of global laws, the promotion of shared understandings, and the efficiency of economic transactions" (Etzioni 2008: 124).

In my view, as a global process, the appearance of the pictorial characteristic of primary communal languages can contribute to the adoption of an additional global language, because this process, as we have seen, creates the foundations of the convergences of different usages and languages. The global expansion of the pictorial language of electronic communication can be regarded as the basis of the idea of a global information community in which the communication attitudes of a person are determined by his impression of his self as a permanently available person whose communicative acts are embedded in a global information net. In other words, it is by accelerating and mediating linguistic changes leading to a complex notion of global community that electronically mediated communication becomes a source of, as Meyrowitz writes, the "fusion of local and global identities"(Meyrowitz 2005: 30) and, thus, the adoption of the idea of a secondary global language in new, mediated communities.

\section{Conclusion}

This essay holds that a new world of communication is in the making. The global linguistic changes traceable to the use of electronic communications technologies lead to a linguistic galaxy which can contribute to the development of higher level of human cohesion. Through the appearance of this linguistic galaxy, a new, mediated kind of community comes into existence which can offer a solution to the balance of power between the dual system of globalization and localization, and also to the fragmentation and segmentation of the globalizing world. In other words, with the worldwide expansion of the new communication culture, a global-community-consciousness can be born that could arrange the values of the global and local worlds into a harmonic unified whole.

\section{References}

Castells, M. (2000). The Information Age Vol. I: Rise of the Network Society. Malden, MA: Blackwell.

Crystal, D. (2004). Language and the Internet. Cambridge: Cambridge University Press.

Deegan, M. (2000). Introduction. In F. Condron - M. Fraser - S. Sutherland (Ed.), CTI /= Computer in Teaching Initiativel Textual Studies: Guide to Digital Resources for the Humanities (pp.1-12). Oxford: University of Oxford Press. 
Etzioni, A. (2001). The Monochrome Society. Princeton, NJ: University Press.

Etzioni, A. (2008). A Global, Community Building Language?, International Studies Perspectives, 2, 113-127.

Gergen, K.J. (2003). Self and Community in the New Floating Worlds. In K. Nyíri (Ed.), Mobile Democracy: Essays on Society, Self and Politics (pp. 103-114). Vienna: Passagen Verlag.

Green, N. (2003). Community Redefined: Privacy and Accountability. In K. Nyíri (Ed.), Mobile Communication: Essays on Cognition and Community (pp. 43-56). Vienna: Passagen Verlag.

Haythornthwaite, C. and Kendall, L. (2010). Internet and Community. American Behavioral Scientist 53(8), 1083-1094.

Katz, J. E., Rice, R.E., Acord, S., Dasgupta, K. and David, K. (2004). Personal Mediated Communication and the Concept of Community in Theory and Practice. In R. Kalbfleisch (Ed.), Communication and Community: Communication Yearbook 28 (pp. 315-371). Mahwah, NJ: Erlbaum.

Kerckhove, de D. (1995). The Skin of Culture: Investigating the New Electronic Reality. Toronto: Somerville House.

Levinson, P. (1999). Digital McLuhan: A Guide to the Information. London: Routledge.

McLuhan, M. (1962). The Gutenberg Galaxy. London: Routledge \& Kegan Paul.

McLuhan, M. (1964). Understanding Media. New York: Mentor.

McLuhan, M. - Fiore Q. (1967). The Medium is the Massage. London: Penguin Books.

Meyrowitz, J. (2005). The Rise of Glocality: New Senses of Place and Identity in the Global Village. In K. Nyíri (Ed.), Sense of Place: The Global and the Local in Mobile Communication (pp. 21-30) Vienna: Passagen Verlag.

Milroy, J. and Milroy, L. (1991). Authority in Language. London - New York: Routledge.

Ong, W.J. (1982). Orality and Literacy: The Technologizing of the Word. London: Methuen.

Poster, M. (2001). What's the Matter with the Internet? Minneapolis MN: University of Minnesota Press.

Tönnies, F. (2001). Community and Civil Society. Cambridge: Cambridge University Press.

Trudgill, P. (1975). Accent, Dialect and the School. London: Edward Arnold.

Wellman, B. and Gulia, M. (1999). Net Surfers don't Ride Alone: Virtual Community as Community. B. In Wellman (Ed.), Networks in the Global Village (pp. 331-367) Boulder, CO: Westview Press. 